\title{
Sistema Eletrônico de Revistas da UFPR
}

www.prppg.ufpr.br

A Universidade Federal do Paraná instituiu o Sistema Eletrônico de Revistas (SER), através do qual abre um importante canal de interação entre usuários e a comunidade cientifica em geral. Neste espaço estão listadas as Revistas Técnico-Científicas publicadas com recursos próprios ou com recursos do programa de apoio à publicação instituído pela UFPR.

O SER utiliza-se do Open Journal System, que é um software livre e com protocolo internacional, permitindo a submissão de artigos e o acesso às revistas de qualquer parte do mundo. Nesse sistema estão cadastradas 28 revistas da UFPR, abrangendo diversas áreas de conhecimento. O DEPARTAMENTO DE INFORMÁTICA da UFPR está encarregado da implantação e gerenciamento do Sistema.

O Sistema pode ser acessado por AUTORES, para a submissão de trabalhos, CONSULTORES, para a avaliação dos trabalhos, EDITORES, para o gerenciamento do processo editorial e USUÁRIOS em geral, interessados em acessar e obter CÓPIAS de artigos já publicados nas revistas.

A SUBMISSÃO de artigos é feita por meio eletrônico e o autor poderá fazer o ACOMPANHAMENTO passo a passo do processo de AVALIAÇÃo por parte dos consultores, até a editoração final do artigo. As NORMAS de publicação e demais instruções aos autores, bem como os endereços dos editores são encontrados nas páginas de cada revista. 